\title{
Possible causes of aberrations in adverse grouping behavior of dairy cows: A field study
}

\author{
G. van Schaik, ${ }^{1,2 *}$ ๑ P. Seinen, ${ }^{1}$ J. Muskens, ${ }^{1}$ T. van Erp, ${ }^{1}$ J. Keurentjes, ${ }^{1}$ A. Huss, ${ }^{3}$ and H. Kromhout ${ }^{3}$ ๑ \\ ${ }^{1}$ Royal GD, Deventer 7400AA, the Netherlands \\ ${ }^{2}$ Department of Population Health Sciences, Faculty of Veterinary Medicine, Utrecht University, Utrecht 3508TD, the Netherlands \\ ${ }^{3}$ Institute for Risk Assessment Sciences, Faculty of Veterinary Medicine, Utrecht University, Utrecht 3508TD, the Netherlands
}

\begin{abstract}
In the Dutch national surveillance system, an increasing number of reports were received in the summer of 2017 from farmers about unusual behavior of their cows. The cows were grouping during the day in summer in one part of the barn and did not move for several hours, which, according to the farmers, led to reduced food and water intake and lying time and resulted in decreased milk production and increased risk of lameness. Many farmers perceived magnetic fields from, for instance, high-voltage lines, automated milking systems, or solar panels as possible causes for the behavior of their cows. Our aim for the study was to study potential factors such as magnetic fields and other factors such as barn climate and insect burden for adverse grouping behavior of dairy cows in the barn. For each case herd, 2 control herds were selected in the same postal area code. A case was a herd in which cattle grouped at least on 7 occasions in a month for several hours. In a control herd, the cows were in the barn during the same time period as in the matching case herd but did not show adverse grouping behavior. A questionnaire was administered by telephone in 31 case herds and 62 control herds. The questionnaire gathered information on behavior of the cows and potential risk factors. In addition, data on the distance of the herd to high-voltage lines was obtained. From a total of 74 variables, all variables with a $P$-value $\leq 0.10$ were included in full multivariable logistic regression model. Backward selection was carried out at $P \leq 0.10$. The grouping behavior of the cows started in most herds in June, was seen only during the day, and lasted mostly 6 to $8 \mathrm{~h}$, with cows often grouped in the northern part of the barn. Identified risk factors appeared to be recently constructed barns, measured stray voltage in barns, and presence of fans in barns. Given the cross-sectional design of the case-control study, causality for these risk
\end{abstract}

Received July 10, 2020.

Accepted November 14, 2020.

*Corresponding author: g.v.schaik@gdanimalhealth.com factors leading to adverse behavior of the cows could not be proven. Dissemination of the results to farmers hopefully results in measures that can prevent the unusual grouping behavior of cows.

Key words: adverse grouping behavior, dairy cows, risk factors

\section{INTRODUCTION}

In the Netherlands, a national surveillance system is in place for early detection of emerging diseases and new phenomena in farm animals (Kock and Deterink, 2011; Santman-Berends et al., 2016). A telephone helpdesk is available for farmers, veterinarians, and other animal health advisors to ask for advice and at the same time provide signals from the field about possible emerging disease incursions (Van Wuijckhuise et al., 2011). In the spring and summer of 2017, over 50 reports were received about adverse grouping behavior of dairy cows in barns. The cows were reported to move to one part of the barn and did not move from that location for at least several hours. The cows probably ate or drank less and probably stood for a long time, as not enough cubicles were available in that area for all cows to lie down at the same time, which is considered harmful for cattle health and welfare (Fregonesi et al., 2007). For instance, farmers complained about decreased milk production and more lameness as a result of the change in behavior. Some farmers reported that this behavior was observed several times in the previous years. The farmers indicated that they believed magnetic fields from, for example, high-voltage power lines, automated milking systems, or solar panels might be possible causes for the behavior of their cows. Therefore, a study was initiated in the spring of 2018 to describe this adverse behavior and to investigate the possible causes.

In literature, little can be found about unusual grouping behavior of cows. When hypothesizing about possible causes, one can think of factors causing fear or discomfort, such as fear-eliciting smells, sights, sounds, or sensations, resulting in avoidance behavior. Two studies from the Czech Republic investigated the dis- 
tribution of cows in a barn during summer and related it to the air temperature and the time of day (Erbez et al., 2012; Javorová et al., 2014). They found that, when the temperature was above $20^{\circ} \mathrm{C}$, the cows were grouping. They hypothesized that avoiding heat as well as stinging insects might be the cause of this behavior. Stinging insects are known to cause grouping behavior of cattle, known as bunching (El Ashmawy et al., 2019).

Another hypothesized cause of unusual grouping behavior may be stray voltage, for which cows are very sensitive (Erdreich et al., 2009). Several studies report the effect of stray voltage on cow behavior and health (Reinemann, 2012), but these studies were usually experimental or consider stray voltage only in the milking parlor (Aneshansley et al., 1992). No study explicitly reports grouping behavior of cows in a barn as a result of stray voltage. In literature the alignment of cows along magnetic field lines is deliberated (Begall et al., 2011; Hert et al., 2011). However, no grouping of cows along magnetic field lines nor as a result of strong magnetic or electric fields (e.g., high-voltage power lines) has been published. The aim of our study was to describe the adverse behavior in more detail and investigate potential factors associated with grouping behavior of Dutch dairy cows.

\section{MATERIALS AND METHODS}

Early in 2018, this study was advertised in farmer magazines. Farmers were asked to contact the telephone helpdesk of Royal GD (Deventer, the Netherlands) when they had observed adverse grouping behavior of their dairy cows in the barn in 2017. Eight farmers contacted Royal GD in 2018. In addition, 47 farmers who had reported the adverse behavior in 2017 were contacted, and, of these, 23 were willing to participate in the study (response rate 49\%). We aimed for a sample size of at least 30 case herds and 2 control herds per case (60 control herds in total) to be able to determine risk factors with an odds ratio (OR) of 2 to 3 , with $95 \%$ confidence.

The case definition was dairy herds in which, in 2018, according to the farmer and his or her veterinary practitioner, cattle would group in one part of the barn for at least $7 \mathrm{~d}$ (not necessarily consecutive) within one month for several consecutive hours. The 2 control herds matched to the case herd were dairy herds in the same 4-digit postal area code in which cows would be in the barn at least the same part of the day and had never shown adverse grouping behavior according to the farmer and his or her veterinary practitioner.

All case farms were asked to maintain a log for one week on 3 different occasions: the first was the week when the adverse behavior occurred in 2018; the second week was the week of Jul. 30 to Aug. 5, 2018; and the third was the week from Sep. 3 to 9, 2018. In the log, farmers had to register the date, the hours of the day that the behavior started and waned, and a description of the behavior. In addition, the farmers were asked to log possible causative circumstances for the change to adverse behavior on or around the farm. To structure this, the farmers were asked to think in the senses of the cows: sight, hearing, smell, and sensation. For each of the senses, examples were provided-for instance, unfamiliar noises, sights or smells, vibrations, heat, pain. At the last day of the week, the farmers were asked whether they had taken any measures to mitigate the behavior and what the effect had been. The log could be filled on a paper form as well as digitally in an online form.

A questionnaire was developed in Survalyzer software (Survalyzer AG, 2018) that contained 74, mainly closed, questions about general farm characteristics, characteristics of the grouping behavior, all possible hypothesized risk factors for the adverse behavior of the dairy cows, and whether the behavior had an effect on health and welfare of the cows. Hypothesized risk factors were related to the construction of the barn (e.g., construction date, roof construction, material of the trusses, type of floors, grounding) and barn equipment (e.g., type of cubicles, drinkers, fans, automated feeders), whether new additions had been made to the barn or new equipment installed, insect pressure and control, solar panels on the roof or in the neighborhood, neighborhood high-voltage lines, transmission towers, or radar equipment, and whether farmers had had investigations done by consultants for stray voltage, magnetic fields, water veins, or earth rays. The farmers of the case herds were asked to describe the most recent event of adverse behavior. In addition, farmers were asked for their consent to obtain data about the geographical location of their herd, to be able to estimate distances to neighboring herds and overhead power lines. The questionnaire was administered by the co-authors JM and TvE by telephone during 2018. The case herd farmers and their matching control herd farmers were called in the same week. The full questionnaire can be obtained upon request from the first author.

All analyses were carried out with STATA version 15 (StataCorp., 2017) following the procedure described by Dohoo et al. (2009). Distance from herd location to closest power lines was extracted using ArcGIS 10.5 (https://desktop.arcgis.com/en/), using topographical maps that include location of overhead power lines in the Netherlands. These were expanded with information regarding voltage levels. The dependent variable in 


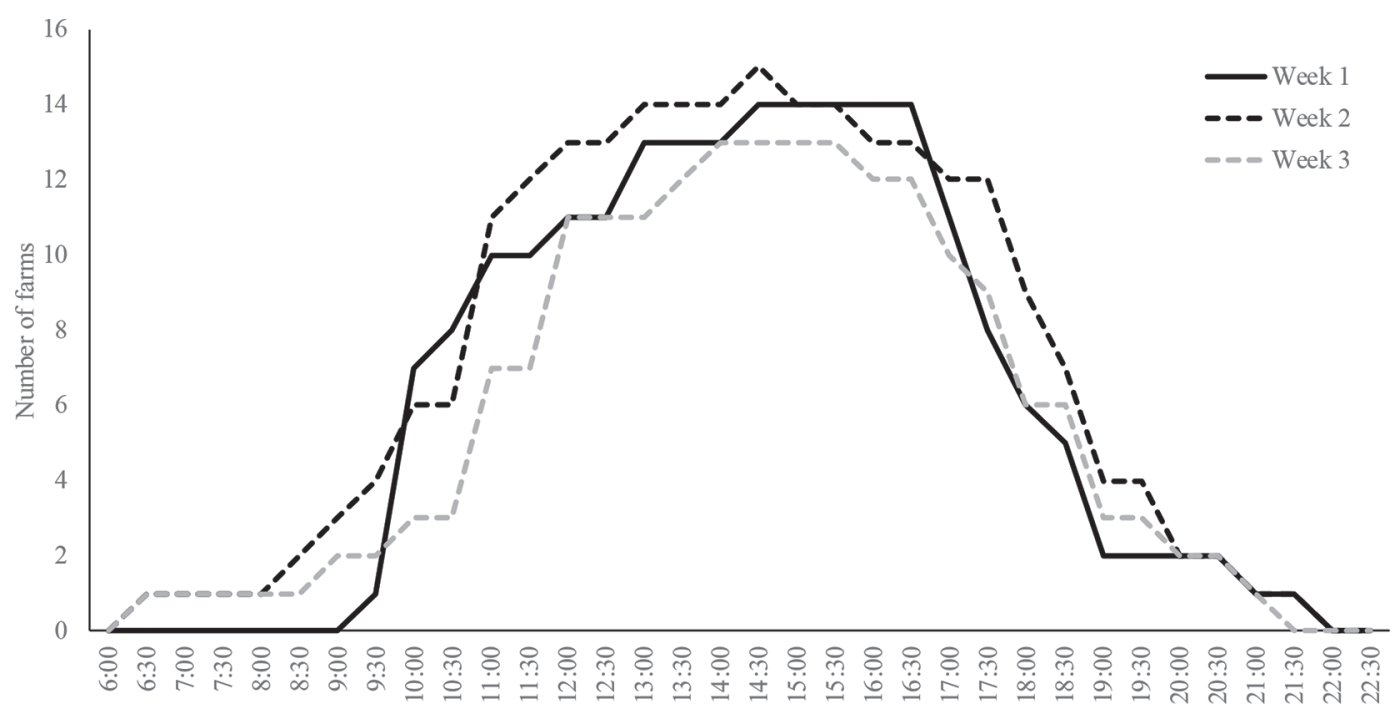

Figure 1. Distribution of the starting and ending time of day of adverse grouping behavior of cows in Dutch dairy herds on the first day of occurrence of this behavior (wk $1, \mathrm{n}=14$ herds), a day in the week of Jul. 30 to Aug. 5 (wk $2, \mathrm{n}=15$ herds), and in the week from Sep. 3 to 9 (wk $3, \mathrm{n}=15$ herds) in 2018.

the analyses was the case or control status of the farm. First, univariate logistic regression analyses were carried out for the cases (1) and controls (0) with $\chi^{2}$ test for all levels of the categorical variables. Initially, the explanatory variable was considered in the multivariable logistic regression model at $P \leq 0.20$. However, a full model based on the variables significant at $P \leq 0.20$ would not converge due to the large number of explanatory variables and the fairly small number of herds in the study. Therefore, the initial screening of variables for the full multivariable model was performed at $P \leq$ 0.10 , whereas, normally, higher $P$-values would be used to avoid type-2 errors (Dohoo et al., 2009). Multicollinearity between explanatory variables was checked with Pearson's correlation coefficients and when $r>$ $|0.3|$, with only the explanatory variable with the strongest association with the case-control status kept for the full model. A backward elimination approach with $P \leq 0.10$ was used to obtain the final model. Confounding was checked by removing the variables in the final model one at a time and considering whether at least one of the coefficients changed more than 25\% (Dohoo et al., 2009).

\section{RESULTS}

In total, 31 case herds participated in the study: 8 herds that self-reported adverse behavior of their cattle in 2018, and 23 of 47 herds that self-reported in 2017. Only 24 of the 31 case herds were willing to keep a $\log$, and eventually the logs of only 18 case herds were submitted. For each case herd, 2 control herds were contacted, and 62 questionnaires were obtained from control herds.

\section{Logs}

The date of the first occurrence of adverse grouping behavior varied from May 1 to Jul. 22, 2018. The average duration of the behavior was $7.5 \mathrm{~h} / \mathrm{d}(95 \%$ CI 6-9 h), varying from 2 to $12 \mathrm{~h} / \mathrm{d}$. In the second week in August, farmers reported that the average duration was slightly longer at $8 \mathrm{~h}(95 \%$ CI $6.5-9.5 \mathrm{~h})$, and in the third week in September the duration was slightly shorter, with, on average, 6 h (95\% CI 2-8 h). Figure 1 shows the distribution of the time of day when the behavior starts and stops for the case herds that provided this information.

Table 1 provides more detailed information from the farmers about the adverse grouping behavior. The majority of the farmers (87\%) perceived the adverse behavior as unfavorable for cow health. They reported more claw problems ( $52 \%$ of the farmers), more mastitis $(19 \%)$, and decreased milk production (65\%).

When asked what changes may have occurred before the cows started to group in an unusual manner, the 31 farmers reported occupying a new barn (19\% of the farmers), installation of an automated milking system $(6 \%)$, and changes to very sunny $(65 \%)$, warm and humid (45\%), or warm and dry weather $(7 \%)$. 
Table 1. Description of the characteristics of adverse grouping behavior of dairy cows in 31 Dutch dairy herds in 2018

\begin{tabular}{|c|c|c|}
\hline Characteristic & Category & $\%$ \\
\hline \multirow[t]{2}{*}{ Adverse grouping behavior observed in 2018} & Yes & 87.1 \\
\hline & No & 12.9 \\
\hline \multirow[t]{2}{*}{ Proportion of cows that group together in one part of the barn } & $<90 \%$ & 22.6 \\
\hline & $>90 \%$ & 77.4 \\
\hline \multirow[t]{8}{*}{ Location in the barn where cows group } & North & 41.9 \\
\hline & Northeast & 12.9 \\
\hline & East & 9.7 \\
\hline & Southeast & 6.5 \\
\hline & South & 0.0 \\
\hline & Southwest & 9.7 \\
\hline & West & 16.1 \\
\hline & Northwest & 6.5 \\
\hline \multirow[t]{4}{*}{ Characteristics of grouping location } & Dark/cool & 18.8 \\
\hline & Light/warm & 37.5 \\
\hline & More ventilation & 25.0 \\
\hline & Less ventilation & 18.8 \\
\hline \multirow{3}{*}{ Other herds in the neighborhood with adverse grouping behavior } & Yes & 19.4 \\
\hline & No & 58.1 \\
\hline & Unknown & 22.6 \\
\hline
\end{tabular}

\section{Case-Control Questionnaire}

Farmers reported that the adverse grouping behavior had started between 2006 and 2017. Fourteen case herds reported it to have started in the preceding years $2015(\mathrm{n}=6), 2016(\mathrm{n}=5)$, or $2017(\mathrm{n}=3)$. Cases were reported from 10 out of 12 provinces in the Netherlands. The 2 provinces (Zeeland and Zuid-Holland) that were absent contain a smaller part of the dairy herd population ( $1.3 \%$ and $7.2 \%$, respectively). The proportion of cases from one province (Noord-Brabant) was much higher than expected. Of the cases, 39\% were from the province of Noord-Brabant, which contains about $14 \%$ of the national dairy herd population (https://opendata .cbs.nl/statline/\#/CBS/nl/dataset/80780ned/table?ts $=1611321038149)$. Descriptive statistics of cases, controls, and all Dutch dairy herds (www.crv4all.nl; www .stichtingkom.nl; https://opendata.cbs.nl/statline/\#/ $\mathrm{CBS} / \mathrm{nl} /$ dataset $/ 80274$ ned/table $? \mathrm{ts}=1611321544835$ ) are provided in Table 2. Herd size, milk production, and outdoor grazing were not statistically different between the cases and controls. Cases had an automated milking system 2 to 3 times more often than did controls.
All risk factors that were statistically significant at $P$ $\leq 0.10$ in the univariable logistic regression analyses are reported in Table 3. Farmers with herds that showed adverse grouping behavior more often had consultants monitoring magnetic fields or stray voltage, and, less frequently, dowsing for water veins and earth rays. The Pearson correlation for investigating stray voltage or magnetic fields and dowsing for water veins and earth rays was high. For stray voltage, the correlation ranged from 0.54 for magnetic fields to 0.56 for earth rays. For magnetic fields, 0.71 for earth rays and 0.62 for water veins, and, for earth rays, 0.71 with water veins. Investigation of stray voltage had the strongest association with the case-control status and was thus retained in the full model. The case farms also had automated milking systems or fans in the barn more often than did control farms. Noise from airplanes or busy roads was more often reported at the control farms.

Table 4 contains the results of the final multivariable model. Three parameters were significantly different between the case and control herds. The OR for herds that had stray voltage investigated and did apply measures to eliminate stray voltage (e.g., grounding)

Table 2. Descriptive statistics of herds with (cases) or without (controls) adverse grouping behavior of dairy cows and all dairy herds in the Netherlands in 2018

\begin{tabular}{lrrr}
\hline Item & $\begin{array}{c}\text { Cases } \\
(\mathrm{n}=31)\end{array}$ & $\begin{array}{c}\text { Controls } \\
(\mathrm{n}=62)\end{array}$ & $\begin{array}{c}\text { All herds } \\
(\mathrm{n}=16,053)\end{array}$ \\
\hline Average number of lactating cows & 125 & 121 & 100 \\
Average milk production (kg per cow per yr) & 9,220 & 9,447 & 9,123 \\
Percentage with automated milking system & 58 & 29 & 25 \\
Percentage that graze their cows & 48 & 61 & 80 \\
\hline
\end{tabular}


Table 3. Statistically significant $(P \leq 0.1)$ risk factors from univariate analyses ( $\chi^{2}$ test) for the presence of adverse grouping behavior of cows $(\mathrm{n}=31$ case herds) and dairy herds without this behavior $(\mathrm{n}=62$ control herds) in 2018

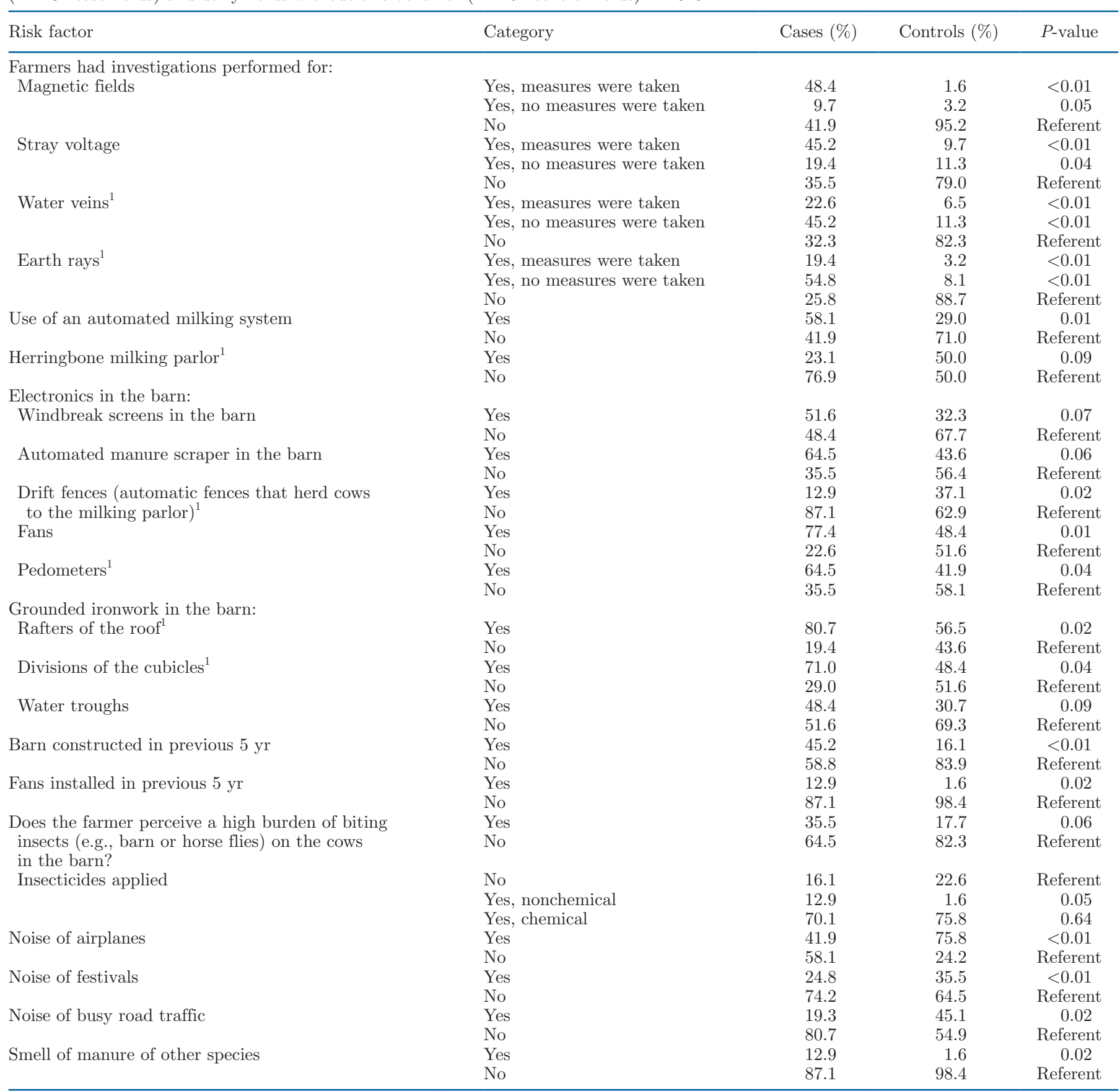

${ }^{1}$ Variables not included in the full model due to multicollinearity.

was higher than the reference at 8.6 (95\% CI 2.4-30.5), whereas the OR for herds that had stray voltage monitored but did not apply measures was not significantly different from the reference. Both the presence of fans in the barn as well as housing cows in a recently constructed barn were associated with higher odds to be a case farm (OR respectively 3.3 and 4.9).

\section{DISCUSSION}

The aim of the study was to obtain insight into factors in the barn environment that may be associated with adverse grouping behavior of dairy cows. The adverse grouping behavior was often characterized as involving over $90 \%$ of the lactating cows grouping in 
one part of the barn for a prolonged period of time. Farmers reported the grouping to occur during the day only, in summertime, for an average of about $8 \mathrm{~h}$, and often in the northern part of the barn. The case farmers mentioned commissioning a new barn or an automated milking system, bright sunlight, and hot and humid weather as possible changes before the start of the adverse grouping behavior. They considered the grouping detrimental for animal health and welfare. However, their observation could not be verified with objective data on the health and productivity of the cows.

The case-control study on 31 cases and 62 control herds resulted in 3 potential risk factors for the adverse grouping behavior. The case farms had a recently constructed barn (less than 5 years old) almost 5 times more often than the control farms. Whether the barn itself causes the cows to group or whether other aspects of that barn are the real cause is unclear. In the Netherlands, the number of newly constructed barns for dairy cows increased around the abolishing of the milk quota system in 2015. This may explain why the number of reports about adverse grouping behavior increased. However, the increase in reports may also be due to increased media attention, which itself causes more reports.

The presence of fans in the barn was another risk factor, and we can only speculate about the reasons. The fans may be an indication of a suboptimal climate in the barn, which causes cows to group to avoid the hottest spots in the barn. Fans are also electronic devices that can cause stray voltage when in use and when not properly grounded. Additionally, fans can produce noise that may annoy the cows or may be installed to repel biting insects. Grouping behavior of cows as a result of biting stable flies has been observed in California and described by El Ashmawy et al. (2019). Interestingly, relative to control farms, the case farms more often mentioned a high burden of flies but less often applied insecticides or applied only nonchemical insecticides (Table $3 ; P \leq 0.10$ ), but these factors were not retained in the final multivariable model. Thus, fans may be a confounder for the aforementioned factors or for another unknown factor that causes the adverse grouping behavior. Case farms more often had consultants investigate stray voltage $(65 \%)$ than did control farms (21\%), but on case farms consultants investigated magnetic fields and earth rays or water veins even more often than on control farms. However, in the final model only investigation of stray voltage was retained. Farmers most often had investigations for magnetic fields, earth rays, and water veins done at the same time. When investigations were done, we could not be sure whether they were performed by a reliable organization or qualified person, nor whether stray voltage was detected. As a proxy, we asked whether measures for stray voltage were taken or not, assuming that measures would be taken only when stray voltage was detected. Farms in which stray voltage was investigated and measures to eliminate stray voltage were applied had a significantly higher OR to be a case farm than a control farm. Stetzer et al. (2016) describe common misconceptions about stray voltage in dairy herds, which may explain why, even though parties investigated stray voltage in the herds, the problem was not solved. The causality of this factor remains unclear. Possibly, measures were taken unnecessarily, or the measures taken were not effective in reducing stray voltage.

This case-control study could only provide hypotheses for potential causal associations. Further studies with more elaborate designs, such as cohort or randomized intervention studies in which risk factors and behaviors such as grouping are measured longitudinally, would be needed to verify the causality of the presented associations.

Many other factors perceived by farmers to be the cause of the adverse grouping behavior of dairy cows were included in the questionnaire. Often, solar panels on the roof or in the neighborhood were mentioned, but these were actually equally present on case (19\%)

Table 4. Final multivariable logistic regression model with risk factors for the presence of adverse grouping behavior of cows ( $\mathrm{n}=31$ case herds) and dairy herds without this behavior ( $\mathrm{n}=62$ control herds) in 2018

\begin{tabular}{|c|c|c|c|c|}
\hline Risk factor & Category & $\begin{array}{l}\text { Odds } \\
\text { ratio }\end{array}$ & $95 \%$ CI & $P$-value \\
\hline Intercept & & 0.07 & $0.02-0.22$ & 0.00 \\
\hline \multirow[t]{2}{*}{ Investigation for stray voltage performed } & No & Referent & & \\
\hline & Yes, measures applied & 8.6 & $2.4-30.5$ & 0.00 \\
\hline \multirow{2}{*}{ New barn built in the previous 5 yr } & No & Referent & & \\
\hline & Yes & 4.8 & $1.5-15.7$ & 0.01 \\
\hline
\end{tabular}


and control farms (13\%). Also, high-voltage power lines from $50 \mathrm{kV}$ to $380 \mathrm{kV}$ were considered by farmers as a risk. Magnetic and electric fields of those power lines may cause discomfort for cows, but, with distance from the power lines, the strength of electromagnetic fields rapidly declines and is no longer measurable at a distance of 100 to $150 \mathrm{~m}$ (Li et al., 1997). The average distance to the power lines was not different for case and control farms, and only 2 herds were located within a 150-m distance from a power line. One case farm was located $60 \mathrm{~m}$ from a $150-\mathrm{kV}$ power line, and one control farm at $50 \mathrm{~m}$ from a $110-\mathrm{kV}$ power line. It seems unlikely that extremely low-frequency electromagnetic fields from power lines could be the cause of the adverse grouping behavior in dairy herds. In literature, no agreement has been reached on whether grazing cows align to magnetic earth fields or not (e.g., Begall et al., 2011; Hert et al., 2011; Slaby et al., 2013; Weijers et al., 2018). In our study, in $75 \%$ of the case farms, earth rays were investigated, and one-third of those herds applied measures (e.g., placed devices that eliminate magnetic fields). Although only $12 \%$ of control herd farms investigated earth rays, only about one-third of those farms took measures. Investigating earth rays with or without subsequent measures was not associated with grouping behavior in the final multivariate model.

Our study was fairly small, with just 31 case and 62 control herds, and initial screening of variables for the full multivariable model was performed at $P \leq 0.10$, whereas normally higher $P$-values would be used to avoid type-2 errors (Dohoo et al., 2009). Therefore, our study was able to detect neither low-prevalence risk factors nor risk factors with small effects. Compared with the general population of Dutch dairy herds, the case and control herds were more often zero-grazing herds with an automated milking system, with a larger herd size and slightly higher milk production levels (Table 1). The results may therefore not be representative for the Dutch dairy cow sector.

The results of this study may be biased by the fact that the definition of case herds was based on self-reported grouping behavior. Eventually $50 \%$ of the earlier reported cases were willing to participate in the study, and the main reason mentioned by case farmers for the low response rate was the time it would take to keep the logs. Control farms only had to participate in the telephone questionnaire. The participating case farms may have represented the more severe cases of adverse grouping behavior of cows (i.e., selection bias; Dohoo et al., 2009). In addition, owners of case herds may have a better memory of risk factors then owners of control herds, resulting in so-called recall bias (Dohoo et al., 2009). These biases may have led to overestimation of risk estimates of factors in the multivariate model (Dohoo et al., 2009).

The impression from our study is that multiple causes for adverse grouping behavior of dairy cows in the barn may exist. Stray voltage seemed to have played a role, especially when a new barn was commissioned and when electronic devices such as automated milking systems or fans were used. We also found indications that climate in the barn and biting insects played a role in the adverse grouping behavior.

\section{ACKNOWLEDGMENTS}

We thank the farmers for their participation and the Dutch product board for dairy (ZuivelNL, The Hague) for financing this study. The authors have not stated any conflicts of interest.

\section{REFERENCES}

Aneshansley, D. J., R. C. Gorewit, and L. R. Price. 1992. Cow sensitivity to electricity during milking. J. Dairy Sci. 75:2733-2741. https: //doi.org/10.3168/jds.S0022-0302(92)78036-9.

Begall, S., H. Burda, J. Cervený, O. Gerter, J. Neef-Weisse, and P. Němec. 2011. Further support for the alignment of cattle along magnetic field lines: Reply to Hert et al., 2011. J. Comp. Physiol. A Neuroethol. Sens. Neural Behav. Physiol. 197:1127-1133. https: //doi.org/10.1007/s00359-011-0674-1.

Dohoo, I. R., S. W. Martin, and H. Stryhn. 2009. Veterinary Epidemiologic Research. 2nd ed. VER Inc., Charlottetown, PEI, Canada.

El Ashmawy, W. R., D. R. Williams, A. C. Gerry, J. D. Champagne, T. W. Lehenbauer, and S. S. Aly. 2019. Risk factors affecting dairy cattle protective grouping behavior, commonly known as bunching, against Stomoxys calcitrans $(L$.) on California dairies. PLoS One 14:e0224987. https://doi.org/10.1371/journal.pone.0224987.

Erbez, M., K. E. Bøe, D. Falta, and G. Chládek. 2012. Crowding of dairy cows in a cubicle barn during the hot summer months. Arch. Tierzucht 55:325-331. https://doi.org/10.5194/aab-55-325-2012.

Erdreich, L. S., D. D. Alexander, M. E. Wagner, and D. Reinemann. 2009. Meta-analysis of stray voltage on dairy cattle. J. Dairy Sci. 92:5951-5963. https://doi.org/10.3168/jds.2008-1979.

Fregonesi, J. A., C. B. Tucker, and D. M. Weary. 2007. Overstocking reduces lying time in dairy cows. J. Dairy Sci. 90:3349-3354. https: //doi.org/10.3168/jds.2006-794.

Hert, J., L. Jelinek, L. Pekarek, and A. Pavlicek. 2011. No alignment of cattle along geomagnetic field lines found. J. Comp. Physiol. A Neuroethol. Sens. Neural Behav. Physiol. 197:677-682. https://doi .org/10.1007/s00359-011-0628-7.

Javorová, J., M. Velecká, D. Falta, M. Večeřa, J. Andrýsek, S. Studený, and G. Chládek. 2014. The effect of air temperature and time of day on distribution of Czech Fleckvieh cows within the barn. Acta Univ. Agric. Silvic. Mendel. Brun. 62:117-124. https://doi.org/10 $.11118 /$ actaun201462010117.

Kock, P., and A. Deterink. 2011. Stakeholders in monitoring and surveillance of animal health in the Netherlands. Poster presentation. In International Conference on Animal Health Surveillance (ICAHS), Lyon, France. AEEMA, 94704 Maisons-Alfort, France.

Li, C. Y., G. Thériault, and R. S. Lin. 1997. A validity analysis of residential magnetic fields estimated from high-voltage transmission lines. J. Expo. Anal. Environ. Epidemiol. 7:493-504. https:// pubmed.ncbi.nlm.nih.gov/9306233/. 
Reinemann, D. J. 2012. Stray voltage and milk quality: A review. Vet. Clin. North Am. Food Anim. Pract. 28:321-345. https://doi.org/ 10.1016/j.cvfa.2012.03.008.

Santman-Berends, I. M. G. A., H. Brouwer-Middelesch, L. van Wuijckhuise, A. J. G. De Bont-Smolenaars, and G. van Schaik. 2016. Surveillance of cattle health in the Netherlands: Monitoring trends and developments using routinely collected cattle census data. Prev. Vet. Med. 134:103-112. https://doi.org/10.1016/j.prevetmed 2016.10.002.

Slaby, P., K. Tomanova, and M. Vacha. 2013. Cattle on pastures do align along the North-South axis, but the alignment depends on herd density. J. Comp. Physiol. A Neuroethol. Sens. Neural Behav. Physiol. 199:695-701. https://doi.org/10.1007/s00359-013-0827-5.

StataCorp. 2017. Stata Statistical Software: Release 15. StataCorp LLC, College Station, TX.

Stetzer, D., A. M. Leavitt, C. L. Goeke, and M. Havas. 2016. Monitoring and remediation of on-farm and off-farm ground current measured as step potential on a Wisconsin dairy farm: A case study. 1. Electromagn. Biol. Med. 35:321-336. https://doi.org/10.3109/ 15368378.2015 .1089888 .
Survalyzer AG. 2018. Survalyzer survey software. Survalyzer AG, Zürich, Switzerland. Accessed Jan. 21, 2021. https://www survalyzer.com.

Van Wuijckhuise, L., P. Kock, and G. van Schaik. 2011. Communication about the cattle health surveillance system in the Netherlands. Poster presentation. In International Conference on Animal Health Surveillance (ICAHS), Lyon, France. AEEMA, 94704 Maisons-Alfort, France.

Weijers, D., L. Hemerik, and I. M. A. Heitkönig. 2018. An experimental approach in revisiting the magnetic orientation of cattle. PLoS One 13:e0187848. https://doi.org/10.1371/journal.pone.0187848.

\section{ORCIDS}

G. van Schaik () https://orcid.org/0000-0002-0460-2629

H. Kromhout (ㄴ) https://orcid.org/0000-0002-4233-1890 